\title{
ANÁLISE DO DESIGN DAS EMBALAGENS DE FARINHA DE TRIGO INTEGRAL ORGÂNICA E A PERCEPÇÃO DOS CONSUMIDORES
}

\author{
Elisa Jorge Quartim Barbosa \\ FAU USP \\ elisaqb@gmail.com \\ Denise Dantas \\ FAU USP \\ dedantas@usp.br
}

\begin{abstract}
Resumo: Esta pesquisa buscou perceber se os princípios agroecológicos utilizados na produção dos produtos orgânicos industrializados se refletem nas embalagens de farinha integral e se estes são percebidos pelos consumidores. $\mathrm{O}$ método escolhido foi um estudo comparativo entre duas indústrias de alimentos orgânicos, definidas após uma pesquisa de campo, e entrevistas em profundidade com os responsáveis pelo desenvolvimento de embalagens e com os consumidores. Os dados da pesquisa mostraram que não há alinhamento entre o discurso e a prática no que diz respeito à seleção e projeto das embalagens. Também mostrou que os consumidores têm dificuldade em perceber as propriedades da farinha integral orgânica apenas pela embalagem, o que sugere que os quesitos não verbais representados pelos elementos simbólicos e metafóricos, codificados em signos e sintaxes específicas no seu design deveriam ser mais valorizados. Assim como também a localização das informações, como o centro de atenções, a área de maior tensão visual e hierarquia de leitura.
\end{abstract}

Palavras-chave: embalagens, alimentos, orgânicos, percepção.

\begin{abstract}
The research sought to understand whether the agroecological principles used in the production of processed organic products are reflected in wholemeal flour packaging and if these are perceived by consumers. The method chosen was a comparative study between two organic food industries, defined after field research and interviews with the packaging development responsible and the consumers. The survey data showed that there is alignment between discourse and practice with regard to the selection and packaging design. Also showed that consumers have difficulty understanding the organic wholemeal flour properties just by the packaging, which suggests that should be considered the non-verbal questions posed by symbolic and metaphorical elements, encoded in signs and specific design syntaxes, as well as the information location, as the attention center, visual tension area and reading hierarchy.
\end{abstract}


Keywords: packaging, food, organic, perception.

\section{INTRODUÇÃO}

A embalagem é parte integrante da crescente demanda por alimentos orgânicos que vem exercendo grandes mudanças nas indústrias. Os produtos orgânicos possuem, em seu próprio conceito a alimentação saudável e a forma de produção com um menor impacto ambiental, porém não se sabe se isso se reflete nas embalagens de seus produtos.

Esta pesquisa buscou verificar como se dá a percepção do consumidor das especificidades inerentes à farinha de trigo orgânica, pelas suas embalagens. $E$ avaliar se a comunicação das especificidades dos alimentos orgânicos está adequada, com base no que é recomendável na literatura especializada de design de embalagens e na legislação brasileira relacionada à produção de orgânicos e embalagens.

Para isso o método escolhido foi um estudo comparativo entre duas indústrias de alimentos orgânicos, definidas após uma pesquisa de campo. E entrevistas em profundidade com os responsáveis pelo desenvolvimento de embalagens nas indústrias e no escritório de design e com os consumidores.

\section{DESENVOLVIMENTO}

Este artigo apresenta o resultado da pesquisa baseada na questão se o consumidor é capaz de perceber as especificidades inerentes aos alimentos orgânicos, presentes na sua produção, apenas visualizando suas embalagens.

O pressuposto da pesquisa é que as embalagens de farinha de trigo integral orgânica podem não refletir, para o consumidor, as características específicas de produção de seu conteúdo, dificultando a identificação dos seus diferenciais ambientais. Há poucos estudos sobre as embalagens de alimentos orgânicos, por isso, esta pesquisa buscou auxiliar futuras pesquisas acadêmicas sobre este assunto e agregar informações ao campo do design.

O objeto de estudo desta pesquisa são as embalagens de farinha de trigo integral orgânica, produzidas e comercializadas em lojas de produtos naturais e em supermercados na cidade de São Paulo, após a aprovação do selo de certificação de orgânicos pelo Ministério da Agricultura, Pecuária e Abastecimento (MAPA) em 2011, com ênfase nos requisitos ambientais de design aplicados no seu desenvolvimento. As empresas que atenderam aos requisitos acima explicitados foram: Mãe Terra e Via Pax Bio.

Esta pesquisa utilizou métodos de abordagem qualitativa, devido à subjetividade dos dados que não podem ser traduzidos em números, e sim interpretados, atribuindo-se a eles significados.

Para a obtenção dos dados, foi feito um estudo comparativo para descobrir padrões e perceber semelhanças e diferenças dos casos estudados, explicitando as especificidades do design das embalagens de alimentos orgânicos e suas percepções.

Para conhecer melhor a política de desenvolvimento de embalagens, primeiramente foi feito um mapeamento de 2011 até 2013 do que é declarado pela empresa em seus materiais de divulgação, como sites e redes sociais.

A fim de obter detalhes e peculiaridades, foram feitas entrevistas profundidade, semiestruturadas, com pessoas que participaram do desenvolvimento das embalagens e também com consumidores de alimentos industrializados, visando a proporcionar uma 
visão geral das políticas de desenvolvimento de embalagens e a percepção dos consumidores quanto às características inerentes aos alimentos orgânicos.

Foram selecionados consumidores de alimentos, de 25 a 75 anos, que vivem da região da Grande São Paulo, que costumam fazer compras para a sua casa e que não tivessem um conhecimento prévio sobre o que era a pesquisa. Foram realizadas 32 entrevistas no período de julho a setembro de 2013, onde foram apresentadas embalagens de alimentos orgânicos de farinha de trigo, açúcar mascavo, arroz, feijão, cookie, barra de cereais, granola e macarrão instantâneo. Para este artigo serão apresentados os resultados relacionados às farinhas integrais que foram mostradas para sete consumidores.

Os dados de uma entrevista não são suficientes para perceber se o entrevistado identifica ou não um alimento orgânico pela embalagem, pois as perguntas, mesmo abertas, poderiam influenciar as respostas. Por esse motivo, durante a entrevista foi feito um experimento, onde foi apresentado um grupo de embalagens de farinha de trigo integral, sobre uma mesa, podendo assim determinar quais eram as variáveis que influenciam na escolha de um produto.

Foi pedido para que ele separasse as embalagens em dois grupos, saudáveis e menos saudáveis, e depois em orgânicos e não orgânicos. O objetivo era perceber se ele relaciona o alimento orgânico a um alimento mais saudável e o que ele olha na embalagem para separar.

Apenas após o experimento é que foram feitas questões específicas sobre os alimentos orgânicos para um melhor detalhamento da percepção do nível de conhecimento sobre esse tipo de produto.

As entrevistas e os estudos comparativos foram importantes para verificar se há coerência entre o design das embalagens e seu conteúdo, no que diz respeito à especificidades dos alimentos orgânicos, indicando a presença ou não de uma deficiência nesse segmento nos casos estudados.

\subsection{Análise dos dados}

A análise dos dados das entrevistas utilizou o método de análise do discurso e análise do conteúdo. Para a análise do conteúdo, foram definidas categorias de unidades de texto e expressões que emergiram das respostas das entrevistas e baseadas na teoria pesquisada. Para análise do discurso, foram identificados padrões e funções no discurso baseados nos dados que emergiram da análise de conteúdo.

A análise das embalagens de farinha integral pretendeu verificar se os atributos de design presentes nas embalagens são capazes de comunicar as especificidades dos orgânicos. Elas foram feitas com base nas informações não verbais representadas nas embalagens, e por seus elementos simbólicos e metafóricos, codificados em signos e sintaxes específicas. Foram considerados também os padrões primários de varredura do campo e a localização das informações, como o centro de atenções, a área de maior tensão visual e hierarquia de leitura.

A análise da estrutura perceptiva e funcional da embalagem ajudou a extrair dados que possibilitaram a interpretação da comunicação e pregnância das formas. Os valores, analogias e associações foram confrontados com o que foi transmitido pelos consumidores nas entrevistas.

\subsection{Referencial Teórico.}


Para estruturar metodologicamente a pesquisa, foram utilizados os livros de Uwe Flick (2009), Augusto Triviños (1987), Maria Rosa e Marlene Arnoldi (2006) e Martin Bauer e George Gaskel (2002).

Quando abordado o tema de produção de produtos e embalagens com menor impacto ambiental, foi usado o livro Cradle to cradle (MCDONOUGH; BRAUNGART, 2002) que descreve ser possível integrar os sistemas industriais com os naturais. $E$ Haverá a idade das coisas leves (KAZAZIAN, 2005), por fazer uma reflexão sobre os objetos do nosso cotidiano que poderiam se tornar mais leves e duráveis.

Sobre o design de embalagem, foi usado o livro Packaging sustainability (JEDLIČKA, 2009) que dá uma ampla visão de soluções para desenvolver embalagens mais sustentáveis e integradas aos sistemas de produção.

A análise da estrutura visual das embalagens foi fundamentada Gestalt nos livros de Donald Hoffman (2001), Donis A. Dondis (1997) e na semiótica com os livros de Lucrécia Ferrara (1993)e Lucia Santaella (2005).

A estratégia de análise final dos dados, combinando os diversos métodos, foi a de triangulação dos dados colhidos nas entrevistas e na análise das embalagens.

\subsection{Alimentos orgânicos}

Para um alimento ser considerado orgânico, deve ser produzido em um ambiente onde se utilizam como base do processo produtivo os princípios agroecológicos que contemplam o uso responsável do solo, da água, do ar e dos demais recursos naturais, respeitando as relações sociais e culturais. (EMBRAPA, 2008)

Desde janeiro de 2011, é obrigatório apresentar o selo do Sistema Brasileiro de Avaliação da Conformidade Orgânica (SisOrg) na embalagem para que o produto possa ser comercializado em lojas e mercados (MAPA, 2012).

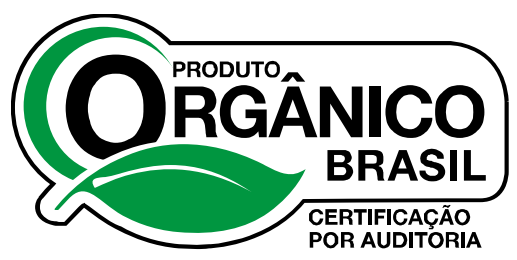

Figura 1- Selo do Sistema Brasileiro de Avaliação da Conformidade Orgânica. Fonte: MAPA, 2009

Com o aumento do uso indiscriminado de agrotóxicos e fertilizantes químicos na agricultura convencional, consumidores de alimentos cada vez mais buscam alternativas para poder se alimentar de forma mais saudável e encontram nos alimentos orgânicos essa opção. $O$ que se destaca no alimento orgânico em relação ao convencional é a ausência de resíduos de agrotóxicos. A embalagem deve expressar visualmente todas as características inerentes ao produto, para que o consumidor o adquira.

\subsection{Design de embalagens de farinha de trigo orgânica.}

Vários autores apresentam considerações acerca do real significado do termo embalagem, porém todos tendem a convergir para um sentido único, onde a embalagem se apresenta como parte integrante de um sistema, considerado como um recipiente de contenção destinado a cobrir, envasar, proteger, manter os produtos. É também uma ferramenta de divulgação, promoção e apresentação do produto (GURGEL, 2007; MESTRINER, 2002; NEGRÃO; CAMARGO, 2008; JEDLIČKA, 2009). 
O design de embalagens deve integrar todas as áreas de desenvolvimento, produção, uso e descarte para que a embalagem possa cumprir eficientemente todas as suas funções. O design é componente integrador do sistema de embalagem, por estar presente desde o início da concepção do produto, durante o qual o tipo e a forma da embalagem são definidos considerando todas as etapas.

Como instrumento comunicacional, e seu aspecto semiológico, o designer (emissor) identifica uma necessidade e elabora o projeto gráfico e estrutural contendo uma mensagem que deve ser apreendida pelo consumidor (receptor) (FERRARA, 1993; GURGEL, 2007; LAUTENSCHLÄGER, 2001; SANTAELLA, 2005).

Quando um indivíduo interage com a embalagem, o resultado desejado pode ser algum tipo de mudança em crença ou no comportamento. Uma abordagem dos fatores humanos pode tornar os projetos de design mais eficazes, ajudando a visualizar e melhorar a experiência do usuário e com o foco nos aspectos físicos e psicológicos ao usar os produtos.

Segundo Dougherty (2011), essa abordagem impulsiona as vendas, desenvolvem o valor da marca e ajudam a determinar o sucesso ou o fracasso de um produto. Aumentar o índice de resposta é uma das ações mais ecológicas que podem ser feitas pelos designers porque ele realmente atinge os resultados desejados.

As escolhas feitas na hora do consumo manifestam a forma como se vê o mundo. O consumo envolve coesão social, produção e reprodução de valores; desta forma, não é uma atividade neutra, individual e despolitizada. Por isso é necessário conhecer o consumidor para o desenvolvimento das embalagens.

É função do designer analisar, interpretar e propor signos que solucionem as necessidades físicas e visuais, otimizando recursos, para obter a embalagem adequada, esperando com isto estabelecer um processo de comunicação e satisfazer as necessidades tanto do fabricante como do consumidor (GIOVANNETTI, 2000).

\subsection{Percepção dos consumidores das especificidades dos orgânicos}

Para esta pesquisa, foram entrevistados 32 consumidores de alimentos industrializados, classificados por perfil de consumo de orgânicos.

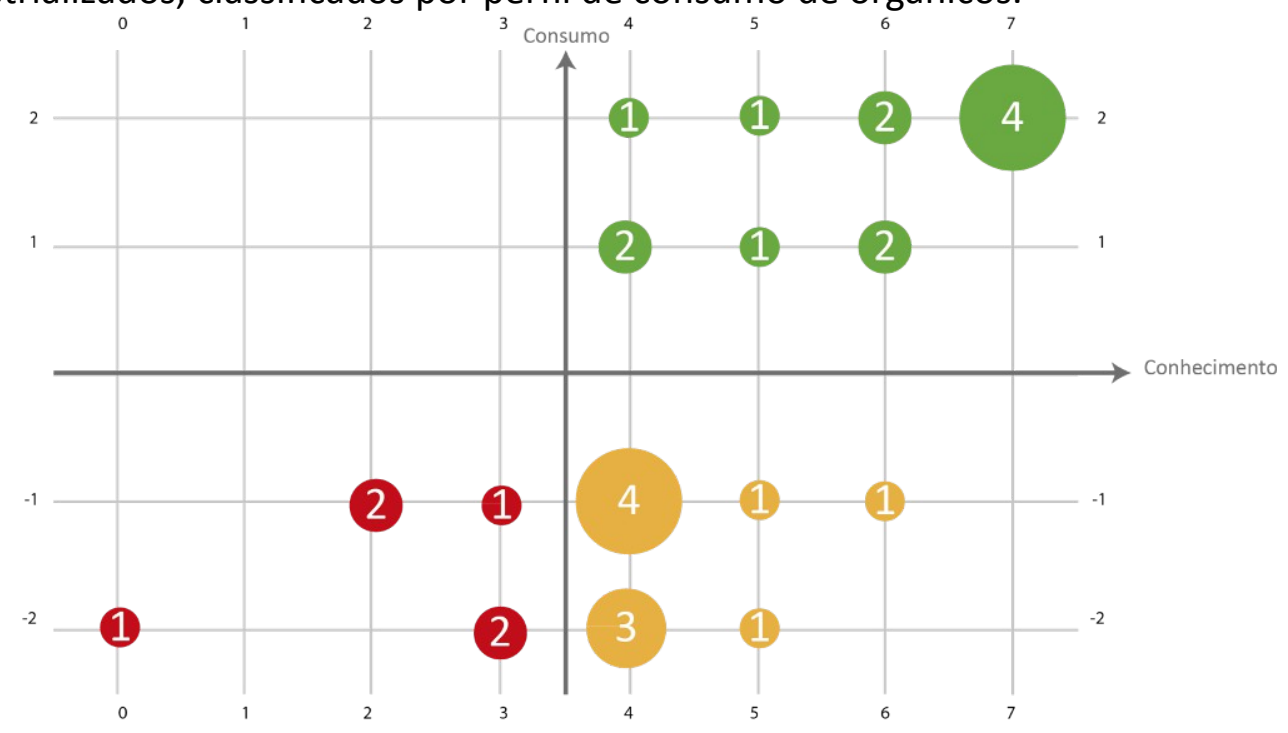




\begin{tabular}{|l|l|}
\hline \multicolumn{2}{|c|}{ Conhecimento do orgânico (um ponto para cada) } \\
\hline Sabe definir & $\begin{array}{l}\text { Impacto menor no meio } \\
\text { ambiente }\end{array}$ \\
\hline Separa corretamente & $\begin{array}{l}\text { Sabe a diferença dos selos } \\
\text { de certificação }\end{array}$ \\
\hline $\begin{array}{l}\text { Identifica ou conhece } \\
\text { o selo SisOrg }\end{array}$ & Conhece uma marca \\
\hline $\begin{array}{l}\text { Identifica ou conhece a } \\
\text { certificadora }\end{array}$ & \\
\hline
\end{tabular}

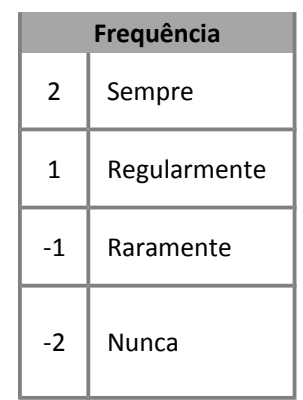

\begin{tabular}{|l|l|}
\hline & $\begin{array}{l}\text { Perfil de consumo } \\
\text { conhece e } \\
\text { consome sempre }\end{array}$ \\
\hline & $\begin{array}{l}\text { Conhece e não consome } \\
\text { (ou consome raramente) }\end{array}$ \\
\hline & $\begin{array}{l}\text { Não conhece e } \\
\text { não consome }\end{array}$ \\
\hline $\begin{array}{l}\text { O tamanho e o número dentro das } \\
\text { circunferências correspondem à } \\
\text { quantidade de consumidores. }\end{array}$ \\
\hline
\end{tabular}

Figura 2 - Perfil do consumidor por conhecimento e frequência de consumo.

Fonte: Elaborado pelo autor, com base na pesquisa realizada.

O objetivo foi verificar se havia diferença entre os consumidores regulares e os que têm pouco conhecimento ou não consomem produtos orgânicos, para que a pesquisa pudesse expressar a opinião dos consumidores em geral. A figura 2 mostra o perfil do consumidor por conhecimento do que é um alimento orgânico por frequência de consumo.

$\mathrm{Na}$ entrevista com os consumidores, foi pedido aos entrevistados que definissem o que é um alimento orgânico. Para avaliar estas definições, foi considerado correto quando as pessoas respondiam pelo menos um dos aspectos da produção orgânica. A grande maioria, 24 das 32 declarações, disse que o alimento orgânico é aquele produzido sem agrotóxico e em segundo lugar, em 19 vezes, ele foi definido como um alimento mais natural, e em terceiro, em 14 vezes como um produto com uma produção diferenciada.

Apenas nove pessoas declararam que a produção do orgânico tem como preocupação a preservação do ambiente em que é produzido, sendo oito consumidores frequentes e apenas um consumidor do grupo com conhecimento, e não consumidor e um do grupo dos não consumidores e com pouco conhecimento.

Mesmo conhecendo um pouco o que é um alimento orgânico, alguns consumidores ainda não consomem com muita frequência. $O$ principal motivo declarado é a percepção de que o alimento orgânico é um alimento mais caro, para poucos: oito dos 29 entrevistados mencionaram o preço do orgânico como algo negativo e três declararam que não consomem por falta de interesse.

Um dos questionamentos analisados na entrevista foi se o consumidor relaciona o alimento orgânico ao alimento mais saudável. Para isso, foi pedido para que ele separasse os produtos apresentados em saudáveis e menos saudáveis. As marcas que os consumidores demonstraram mais dúvida, seja por demorar mais ou por comentarem durante a separação, foi a Jasmine (cinco vezes), a Gran Pure (quatro vezes) e a Mãe Terra (três vezes).

A categoria palavra "orgânico" foi mencionada 42 vezes como critério para a separação, em 58 vezes que foi pedido esse procedimento. O selo de certificação foi mencionado apenas quatro vezes.

No final da entrevista, foi perguntado se o consumidor se lembrava de alguma marca de alimentos orgânicos. A marca mais citada, por 16 consumidores, foi a marca Mãe Terra, por 15 consumidores, e Jasmine e Taeq, empatados com três menções.

A marca também foi a informação mais mencionada como critério para a separação como saudável ou não saudável, aparecendo 19 vezes. A presença de uma marca conhecida fez com que algumas pessoas separassem sem nem mesmo olhar a sua composição, pois confiam nela. 
A marca mais associada aos orgânicos foi a da Mãe Terra, citada por 15 consumidores. Em segundo lugar, aparecem empatadas a Jasmine e a Taeq, com três citações, e em terceiro lugar a Via Pax Bio, com duas citações.

Quando os consumidores conheciam um pouco sobre a marca, mas não consumiam orgânicos com frequência, em dois casos acabaram separando os produtos pela marca, mesmo não sendo.

\subsection{Análise das embalagens de farinha de trigo orgânica}

Para verificar se as embalagens de alimentos orgânicos comunicam a política de desenvolvimento de produtos declarada pelas indústrias, e se os consumidores percebem isso pela embalagem, 7 dos 32 consumidores entrevistados foram postos a manipular embalagens de diferentes farinhas integrais orgânicas e não orgânicas.

A marca de farinha de trigo integral separada como mais saudável foi a da Via Pax Bio, por seis de sete consumidores. Os principais critérios para a separação foram: ter a palavra "orgânico" (cinco consumidores), a composição nutricional (três consumidores) e a marca (dois consumidores).

As marcas de farinha de trigo integral separadas como orgânicas foram a Via Pax Bio e a Mirella. A Mãe Terra, mesmo sendo orgânica, não foi separada por um consumidor por ele não encontrar a palavra "orgânico", conforme pode ser visto no gráfico abaixo:

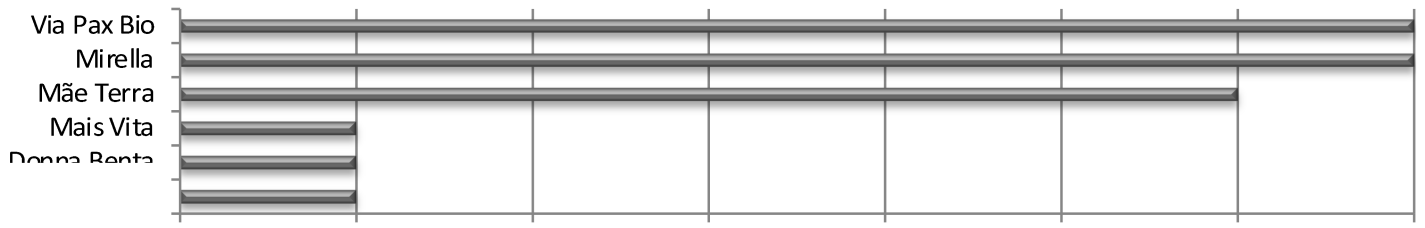

Figura 3 - Marcas de farinha de trigo integral separadas como orgânicas. (unidade $=\mathrm{n}$ ㅇ de consumidores).

Fonte: Elaborado pelo autor, com base na pesquisa realizada.

Para separar em orgânico e não orgânico, a principal informação textual olhada foi a palavra "orgânico", por todos os sete consumidores. O selo de certificação SisOrg apareceu em segundo lugar (três consumidores) como critério de separação.

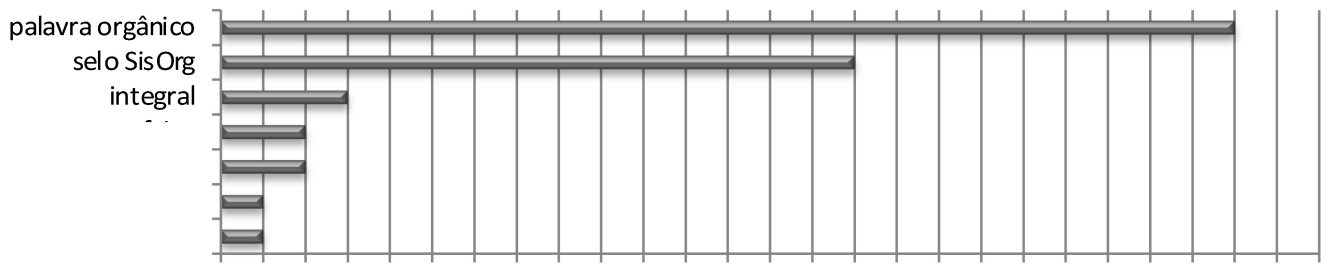

Figura 4 - Critérios para separação de farinha de trigo integral como orgânica. (unidade $=$ no de menções)

Fonte: Elaborado pelo autor, com base na pesquisa realizada.

Com base nos dados apresentados, para identificar como alimento orgânico, a informação textual e o selo SisOrg foram suficientes, havendo pouca dúvida, porém quando a informação era destaca era mais facilmente identificada. 
$\mathrm{Na}$ análise da embalagem de farinha de trigo integral da Via Pax Bio (figura 5) segundo o sentido de leitura, de cima para baixo, da esquerda para a direita, a primeira informação do painel frontal é a marca Via Pax Bio, porém a primeira informação a ser lida é a faixa verde com a palavra "Orgânico", por sua forma diferenciada e cor em contraste com o fundo em degradê do rosa até o branco.

A marca da Via Pax Bio é aplicada sobre um fundo claro, dando boa leitura em contraste com as cores da marca, que são o azul e o verde escuro.

A janela no centro do painel frontal permite visualizar apenas uma pequena parte do produto dentro da embalagem. A escolha do vermelho parece aleatória, não tendo nenhuma relação com o produto, porém como a cor da farinha é quase branca, destacou o produto.

A faixa verde divide ao meio a janela e tem a informação "Orgânico, alimento saudável". Essa faixa verde, por sua forma e cor, é o principal destaque desse painel, sendo mais visível que o nome do produto, mostrando visualmente, principalmente, a importância de ser um alimento orgânico e dando a identidade da linha de produtos, pois se repete em produtos de outras linhas da Via Pax Bio.
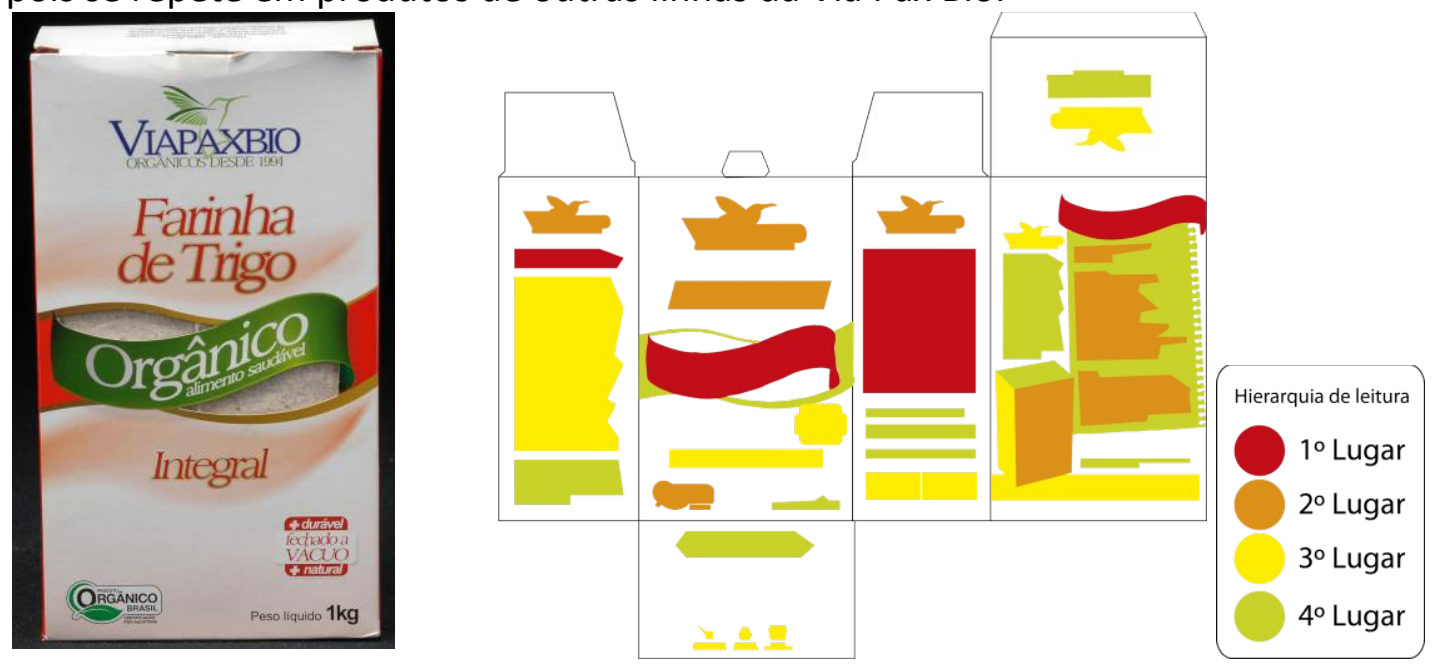

Figura 5 - Embalagem da farinha de trigo integral Via Pax Bio e análise da hierarquia de leitura. Fonte: Elaborado pelo autor, com base na pesquisa realizada.

A classificação do produto fica logo abaixo da faixa verde de orgânico e é feita apenas pela palavra "integral", escrita em um tipo com serifa com as mesmas cores do nome do produto, porém em um tamanho menor. A tipografia escolhida também permite uma boa leitura, seja pelas cores em contraste com o fundo ou por seu tamanho.

Abaixo da classificação do produto, do lado direito, é aplicado o splash com a informação "+ durável. Fechado a vácuo. + natural”. A cor do texto é a mesma cor das laterais da embalagem. Abaixo do splash, é aplicada a informação do peso do produto, em fonte sem serifa e em cor preta.

O selo de certificação de orgânico, SisOrg, é aplicado no canto inferior esquerdo. Se considerarmos o sentido de leitura da embalagem, ele está localizado no canto de pior visualização. Porém, o olho favorece a zona inferior esquerda de qualquer campo visual, segundo o padrão de varredura. A faixa verde localizada no centro geométrico da embalagem faz com que o olho reaja a esse impulso perceptivo. A localização do selo facilita a sua leitura por estar em uma área de grande tensão visual. 
Os elementos gráficos estão em equilíbrio, onde a faixa forma uma linha horizontal marcante e a composição centralizada, simétrica e regular, forma uma linha vertical imaginária no centro, harmonizando a sua composição.

A farinha de trigo integral Via Pax Bio segue o mesmo padrão de design dos outros produtos da linha de ingredientes.

Quanto à hierarquia de leitura, o painel frontal é o que contém as principais informações do produto. Os painéis laterais, por sua localização, são lidos em uma segunda etapa, mas a cor chama mais a atenção. A base é o último painel a ser lido, por estar escondido. Na gôndola do supermercado, o produto é exposto na vertical.

$\mathrm{Na}$ análise do conteúdo das entrevistas com os consumidores, conforme podemos ver na figura 6 observa-se que a embalagem de farinha de trigo integral Via Pax Bio foi percebida como positiva por ser orgânica e por estar em uma embalagem fechada a vácuo. Porém, mesmo gostando da embalagem, percebe-se que o consumidor considera a segunda embalagem um desperdício de material e ainda atrapalha a visibilidade do produto, considerada importante para essa categoria.

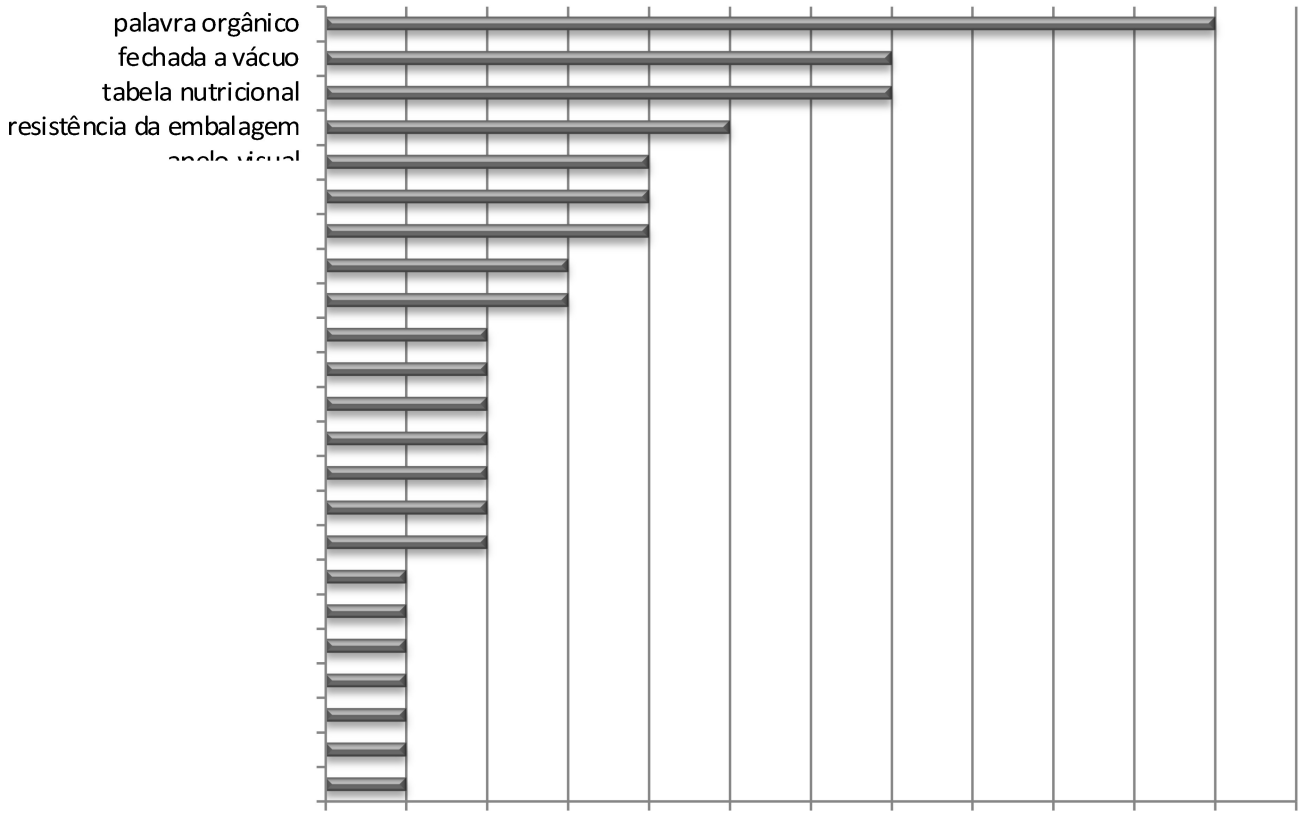

Figura 6 - Aspectos positivos da farinha de trigo integral Via Pax Bio.

(unidade $=\mathrm{n}$ - de menções)

Fonte: Elaborado pelo autor, com base na pesquisa realizada.

$\mathrm{Na}$ análise da embalagem de farinha de trigo integral da Mãe Terra (figura 7), segundo o sentido de leitura, de cima para baixo, da esquerda para a direita, a primeira informação do painel frontal é a marca Mãe Terra. Porém, a ilustração é a primeira informação visual a ser vista, pelas cores em contraste com o fundo branco. A marca é aplicada sobre o fundo banco, dando boa visibilidade e contraste de cor. $\mathrm{O}$ nome do produto em verde, com tipografia de serifas simples, contrasta com a cor do fundo, sendo bem legível. 

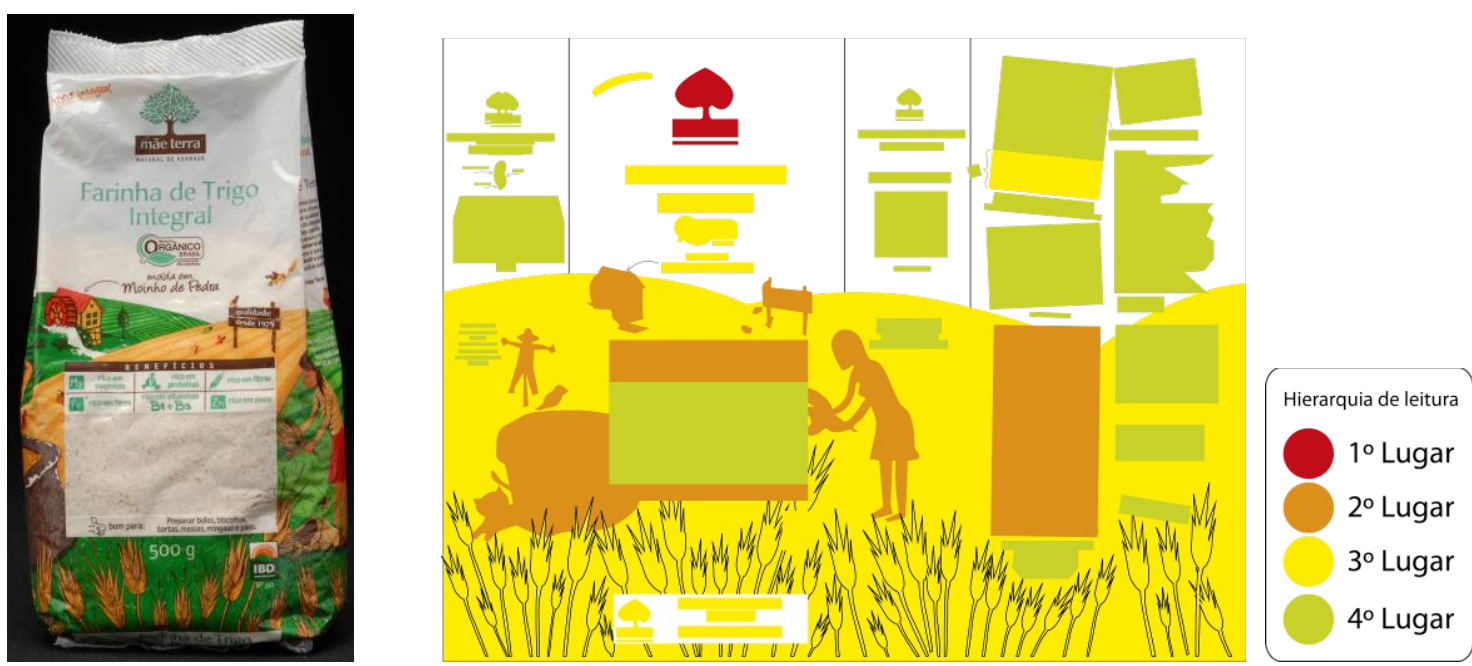

Figura 7 - Embalagem da farinha de trigo integral Mãe Terra e análise da hierarquia de leitura. Fonte: Elaborado pelo autor, com base na pesquisa realizada.

A hierarquia de leitura da embalagem da farinha de trigo integral da Mãe Terra faz com que informações mais relacionadas à marca tenham mais destaque do que as informações mais específicas do produto.

O painel frontal da embalagem da farinha de trigo segue a mesma estrutura visual das outras embalagens da linha de ingredientes da Mãe Terra, porém, neste caso, a ilustração da fazenda foi adaptada ao produto.

O selo SisOrg abaixo do nome do produto tem o mesmo peso visualmente, não se destacando, e por ter outra informação abaixo com o mesmo peso e cor.

Os elementos gráficos estão em equilíbrio, e as informações textuais e gráficas estão centralizadas em relação à embalagem.

\section{CONCLUSÃO}

As considerações finais desta pesquisa sobre os alimentos orgânicos se basearam na legislação brasileira para a certificação de orgânicos. Foi avaliada qual foi a política estabelecida para divulgação dos diferenciais dos orgânicos no design das embalagens de seus produtos, se essa política se reflete nas embalagens e se são percebidas pelos consumidores.

Baseado nas declarações das indústrias, todas as empresas declararam que escolheram produzir alimentos orgânicos por considerarem mais saudáveis e usam isso como estratégia de comunicação.

No que diz respeito à percepção dos consumidores para diferenciar o produto como orgânico e não orgânicos podemos observar que a maioria dos consumidores os identificou principalmente pela palavra "orgânico" na embalagem, mesmo quando não tinha muito conhecimento dos seus diferenciais.

Nos casos em que o consumidor conhecia melhor o que é um alimento orgânico, além de perceber logo a palavra, buscou outras informações relacionadas à produção dos produtos, mostrando que o consumidor mais frequente de orgânicos valoriza outros aspectos do produto além dos nutricionais e da identificação com a marca.

Apenas a embalagem da Via Pax Bio usa como estratégia de divulgação o fato do alimento ser orgânico, sendo essa a informação com mais destaque em suas embalagens. A embalagem da Mãe Terra se limitou em colocar os selos de certificação, 
obrigados pela legislação, no tamanho mínimo permitido e em uma área com pouco destaque, mostrando que priorizam outras informações nas embalagens.

Todas as indústrias, para venderem orgânicos, são obrigadas a utilizar o selo SisOrg, porém o local onde ele é aplicado na embalagem pode facilitar ou dificultar a sua identificação pela hierarquia de leitura. $\mathrm{Na}$ análise das embalagens, foi observado que, quando há muitas informações no painel frontal, o selo perde destaque e visibilidade.

O consumidor, mesmo não o conhecendo, o identificou para separar a embalagem como orgânico, mostrando que o desenho gráfico criado é eficiente na sua função de comunicar e identificar. Sua identificação só foi dificultada nos casos em que estavam localizado em áreas menos visíveis pela hierarquia de leitura.

A embalagem da farinha de trigo da Mãe Terra foram as que mais confundiram os consumidores para identificar se era ou não um alimento orgânico. Alguns consumidores separaram todas as embalagens Mãe Terra como orgânicas por considerarem que é uma empresa que só produz alimentos orgânicos, mostrando que a política de comunicação da marca pode ser tão forte que leva o consumidor a interpretar uma mesma informação para todos os seus produtos, mesmo quando têm características diferentes, como o fato de não serem todos orgânicos. Esse fato pode levá-lo a acreditar que a empresa não é confiável. Identificar e diferenciar o alimento orgânico adequadamente é necessário para haver um consumo mais consciente.

Além de confundirem com a marca, a informação de que o produto é orgânico,

ou não, é muito discreta e sem destaque, dificultando a sua visualização, principalmente quando o consumidor não está procurando especificamente por essa informação, não facilitando a comunicação com consumidores não frequentes.

Considerando o que foi exposto, conclui-se que a forma de comunicar as especificidades dos alimentos orgânicos podem ser mais exploradas nas embalagens e cabe ao profissional de design orientar a empresa de forma adequada, mesmo quando isso não é estabelecido no briefing inicial.

O designer deve investir na parceria com as indústrias e se posicionar como consultor no que diz respeito ao design de embalagens com menor impacto ambiental, mesmo quando o produto não tem essa característica, sendo um integrador das diversas áreas de desenvolvimento de embalagens.

\section{REFERÊNCIAS}

ABRE - ASSOCIAÇÃO BRASILEIRA DE EMBALAGEM. São Paulo, 2010-2011. Disponível em: <http://www.abre.org.br>. Acesso em: 31 jul. 2013.

ANVISA. Programa de análise de resíduos de agrotóxicos em alimentos (PARA). 2011. Disponível em: <http://portal.anvisa.gov.br/>. Acesso em: 29 ago. 2013.

BAUER, M. W.; GASKELL, G. Pesquisa qualitativa com texto, imagem e som: um manual prático. Petrópolis: Vozes, 2002.

BRAUNGART, M.; MCDONOUGH, W. Cradle to cradle: re-making the way we make things. London: Vintage Books, 2008.

DAROLT, M. R. Comparação entre a qualidade do alimento orgânico e convencional. In: STRIGHETA, P. C.; MUNIZ, J. N. Alimentos orgânicos: produção, tecnologia e certificação. Viçosa: Universidade Federal de Viçosa (UFV), 2003, p.289-312. Disponível em: 
<http://www.iapar.br/arquivos/File/zip_pdf/OrgConvenc.pdf>. Acesso em: 10 ago. 2013.

DONDIS, D. A. Sintaxe da linguagem visual. 2. ed. São Paulo: Martins Fontes, 1997.

DOUGHERTY, B. Design gráfico sustentável. São Paulo: Edições Rosari, 2011.

EMBRAPA. Princípios norteadores da produção orgânica de hortaliças. Brasília: 2008.

FERRARA, L. d'A. Leitura sem palavras. 3. ed. São Paulo: Ática, 1993.

FLICK, U. Introdução à pesquisa qualitativa. 3. ed. Porto Alegre: Artmed, 2009.

GURGEL, F. A. Administração da embalagem. São Paulo: Thomson Learning, 2007.

HOFFMAN; D. Inteligência visual: como criamos o que vemos. São Paulo: Campus, 2001.

INSTITUTO DE EMBALAGENS; CAMILO, A. N. (Coord.). Embalagens: design, materiais, processos, máquinas e sustentabilidade. Barueri: Instituto de Embalagens, 2011.

JEDLIČKA, W. Packaging sustainability: tools, systems and strategies for innovative package design. Hoboken: John Wiley and Sons, 2009.

KAZAZIAN, T. (org). Haverá a idade das coisas leves: design e desenvolvimento sustentável. 2. ed. São Paulo: SENAC, 2005.

LAKATOS, E. M.; MARCONI, M. D. A. M. Fundamentos de metodologia científica. São Paulo: Atlas, 1996.

LAUTENSCHLÄGER, B. I. Avaliação de embalagem de consumo com base nos requisitos ergonômicos informacionais. 2001. 109 f. Dissertação (Mestrado em Engenharia de Produção). Universidade Federal de Santa Catarina, Florianópolis, 2001.

MAPA - MINISTÉRIO DA AGRICULTURA, PECUÁRIA E ABASTECIMENTO. Site prefira orgânicos. Disponível em: <http://www.prefiraorganicos.com.br/oquesao.aspx>. Acesso em: 31 jul. 2012.

Ministério da Agricultura, Pecuária e Abastecimento (MAPA). Instrução Normativa no 50/2009, de 29 de maio de 2009. Institui o selo único oficial do Sistema Brasileiro de Avaliação da Conformidade Orgânica. Disponível em: $<$ http://extranet.agricultura.gov.br/sislegis/ action/detalhaAto.do? method=recuperarTextoAtoTematicaPortal\&codigoTematica=1501059>. Acesso em: 15 jun. 2011.

MANZINI, E., VEZZOLI, C. O desenvolvimento de produtos sustentáveis: os requisitos ambientais dos produtos industriais. São Paulo: EDUSP, 2002.

MESTRINER, F. Gestão estratégica de embalagem: uma ferramenta de competitividade para sua empresa. São Paulo: Pearson Prentice Hall, 2007.

NEGRÃO, C.; CAMARGO, E. Design de embalagem: do marketing à produção. São Paulo: Novatec Editora, 2008.

NIEMEYER; L. Elementos de semiótica aplicados ao design. Rio de Janeiro: 2AB, 2003.

ROSA, M. V. de F. P. do C.; ARNOLDI, M. A. G. C. A entrevista na pesquisa qualitativa: mecanismos para validação dos resultados. Belo Horizonte: Autêntica, 2006.

SANTAELLA, L. Semiótica aplicada. São Paulo: Pioneira Thomson Learning, 2005. 
TRIVIÑOS, A. N. S. Introdução à pesquisa em ciências sociais: a pesquisa qualitativa em educação. São Paulo: Atlas, 1987. 